\title{
La última guerra de independencia, desde la perspectiva antillana
}

\author{
Paul Estrade \\ Centro de "Histoire des Antilles Hispaniques" \\ Universidad de París VIII
}

\begin{abstract}
En este estudio se plantea la necesidad de analizar también la guerra de Cuba, al inicio de la misma (1895), desde el escenario antillano y un enfoque antillanista; es decir, desde una perspectiva de reajuste del mundo que tienda a la creación de un Estado soberano, independiente tanto de España como de EE.UU., y de una república moral, justa y democrática, totalmente nueva. Si bien el escenario es disímil y disperso, como eran las Antillas, la aspiración democrática y el proyecto antillanista, expresados por autores y actores del temple de Martí, Gómez, Luperón, Hostos o Betances, le confieren unidad y fuerza a la vía que se estaba buscando mediante la guerra libertadora, fuera de los imperios y los modelos, y que debía desembocar en la Confederación de las Antillas libres. El historiador no puede desconocer la existencia y el poder de semejante sueño entre los combatientes mambises, para entender el sentimiento de frustración que nació también allá a raíz de 1898.
\end{abstract}

Varias son las perspectivas geopolíticas e históricas desde las cuales se puede enfocar legítimamente la última fase de las guerras de la independencia cubana al inicio de la misma en 1895 .

1) Desde la perspectiva cubana, desde luego y ante todo, aunque es una consideración que a veces ha sido pasada por alto en recientes foros internacionales, como si Cuba fuera sólo lugar de enfrentamientos mundiales y no protagonista viva y autónoma. Desde la parte cubana involucrada en la contienda, esa guerra deseada y preparada era la continuación de las anteriores comenzadas en Yara en 1868; el último forcejeo para afirmar la nacionalidad y conseguir el reconocimiento del Estado-Nación gestado a lo largo del siglo.

2) Desde la perspectiva contraria - la española - esa guerra impuesta era un descomunal reto, cuya conclusión podía ser, si se perdiera la guerra (lo que nadie imaginaba), el derrumbe del imperio en América, el hundimiento de la monarquía constitucional, el retroceso de la civilización europea.

3) Desde la perspectiva europea - la de las principales potencias (Gran Bretaña, Francia, Alemania, Rusia, Austria, Italia), que oscilaban entre neutralidad y solidaridad con España (por temor al triunfo cubano o a la intervención norteamericana)—, esa guerra incómoda se apreciaba 
según las consecuencias previsibles que sufriría la correlación de fuerzas a escala internacional en caso de derrota española.

4) Desde la perspectiva norteamericana, esa guerra azuzada por algunos sectores económicos y populares (jingoístas) y frenada en las altas esferas del poder, se veía sin embargo como la oportunidad inesperada de dar cumplimiento a la ley de "gravitación política" de Adams, a la "espera paciente", al "Destino manifiesto", etc., o sea a la aspiración, casi secular, de Jefferson y sus continuadores de convertir a la Antilla mayor en posesión norteamericana.

5) Desde la perspectiva latinoamericana, la guerra renaciente de Cuba debía ser el último golpe dado a la antigua metrópoli obsoleta, la coronación de la gesta bolivariana empezada en 1810, la generalización de la libertad política y la república a todo el Nuevo Mundo. Digo "debía ser" porque si la opinión pública latinoamericana en general y algún que otro gobierno (como el de Ecuador) mostraban simpatía por la causa cubana, a la mayor parte de los gobiernos la guerra les ponía en un aprieto, pues no querían tener que elegir entre EEUU y España, y para algunos pueblos (como el mexicano) el peligro yanqui era tal que la causa española les parecía justa.

6) Desde la perspectiva antillana, compleja por cierto y nada homogénea, por ser las Antillas divididas coto de Europa, parte de América Latina, blanco de EEUU, nudo de contradicciones y objeto de rivalidades imperiales, con la guerra de Cuba renacía para unos una pesadilla, pero para otros una utopía: la posible realización de un destino propio e innovador para todo el archipiélago que había sido el de la destrucción, la esclavitud y la sumisión durante cuatro siglos de explotación colonial bajo uno u otro nombre.

En este caso, como en los anteriores, es obvio que la perspectiva no se abre de la misma manera cuando estalla el Grito de Baire o cuando se hunde la escuadra del almirante Cervera en la bahía de Santiago de Cuba, tres años después. Al inicio de la Revolución de Martí, 24 de febrero de 1895, el triunfo de ésta en Cuba debe acarrear - se presume - cambios radicales en las Antillas tempranamente libres. Al ser derrotada la armada española (el 3 de julio de 1898), apartados de las negociaciones de paz y vejados los mambises, ocupadas militarmente Cuba y Puerto Rico, la libertad de todas las Antillas parece comprometida por un tiempo indeterminado. Ya no hay perspectiva antillana. 
Huelga decir también que, cuando hablamos de perspectiva española o norteamericana -o la que sea, inclusive la asiática no mencionada-, no postulamos que desde un escenario exista sólo una perspectiva y una mirada posible. En cualquier escenario hubo conocimientos y conciencias, intereses y posturas a veces opuestos, que desembocaron en duros enfrentamientos de guerra civil en Cuba, de guerra social sorda en España, de tensión interna en países como EEUU, Francia, Italia y algunos Estados latinoamericanos (como Chile o México), en pro o en contra del statu quo colonial en Cuba. Pero donde mejor queda reflejada esa diversidad de criterios y comportamientos es precisamente en las Antillas.

\section{Desde las Antillas menores aún colonizadas}

El panorama antillano, en 1895, en lo que al sistema de gobierno se refiere, ha evolucionado bastante desde la revolución de Saint-Domingue, pero con la salvedad de las dos repúblicas que comparten la antigua Isla Española, todas las demás islas siguen siendo posesiones coloniales de metrópolis europeas. Por un lado el número de imperios allí presentes va reduciéndose (Suecia renunció en 1876, Dinamarca lo hará en 1917), pero por otro lado van asomando nuevos imperios desprovistos de tierras antillanas cuando el primer reparto, que ahora las codician por sus bases o mercados potenciales. Aprovechando las debilidades de los dos Estados independientes de la zona - Haití y la República Dominicana - y las de la administración de España en las llamadas provincias ultramarinas, Alemania y sobre todo EEUU presionan solapadamente a los imperios arraigados en las Antillas desde tiempo atrás para poder convertirse también, a su vez, en potencias en esa región, estratégica por la proximidad del futuro canal interoceánico. Las obras están paradas, pero nadie pone en duda su conclusión.

No se asemejan los sistemas de dominación colonial que imperan en las Antillas británicas, francesas u holandesas ni por el estatuto otorgado, ni por el grado de representación de la población insular en la metrópoli. Sin embargo, en esas islas la opinión pública, en la medida en que existe (la prensa) y está enterada de los acontecimientos de la mayor de las Antillas, ¿será diferente del eco repercutido y medio absorbido de la opinión pública en aquellas metrópolis? Habría que estudiarlo concretamente en realidad, porque si tales estudios locales, o meros sondeos, se han lleva- 
do a cabo a nivel de tesinas en las universidades caribeñas, permanecen desconocidos para nosotros. Es probable, aunque no se ha comprobado, que esporádicamente en tal o cual isla se haya manifestado algún interés o temor por la guerra desatada en la isla vecina, y se hayan pronunciado unos a favor del orden colonial y otros a favor de la insurgencia. La propaganda española en Europa, según la cual en la manigua cubana los más de los rebeldes eran negros, puede que haya sido contraproducente en aquellas Antillas negras y hasta haya engendrado admiración y celos en individuos de aquella población.

El caso es que, entre los parlamentarios franceses que representaban a la isla de Guadalupe en las Asambleas en París, existió una expresión real de solidaridad con la causa cubana. La apoyaron por ejemplo el diputado Gastón Gerville-Réache y el senador Alexandre Isaac, ambos de la tendencia republicana "radical" y ambos "de color", como se decía. Oigamos a Isaac:

“...Es importante destacar que la situación de estas islitas [está evocando a las francesas] no tiene nada de comparable con la de Cuba, que es un gran país, bastante provisto de recursos de toda clase como para formar una república independiente. Es éste el objetivo que tienen los cubanos, porque no tienen ningún interés en entrar en la confederación americana. Aunque los intérpretes más inmoderados de la doctrina Monroe los empujaran a esta solución, demasiadas razones los harían desistir; entre los anglosajones de la América del Norte, desprovistos del sentimentalismo propio de las razas del sur, y los latinos cruzados con africanos y caribes que componen la población de la isla española no hay fusión posible.

De cualquier modo, España perderá a Cuba, porque ha desconocido el deber de las metrópolis con respecto a ese país, deber que consiste en hacerse amar de sus colonias; porque no supo darle el modo de gobierno que le convenía; porque quiso aplicar a un pueblo audaz [un] sistema de miserable explotación ...

En cuanto a nosotros, espectadores, pero espectadores no indiferentes de la gran batalla que se libra allende el Atlántico [Isaac escribe estas líneas desde París en 1896], no tenemos ninguna razón para tomar partido por una nación cuyo último rey fue coronel de ulanos, y cuyos soldados, si podemos creer noticias recientes, fusilan en Cuba a franceses no combatientes. Podemos mostrar, sin temer que se nos perjudique, nuestras preferencias por los que reivindican los derechos de la patria; todos los franceses que han conservado el culto a la libertad pueden formular votos por la independencia de Cuba". ${ }^{1}$

1 Alexandre Isaac: "Cuba", Le Petit Rouennais, Rouen, junio de 1896. Parcialmente reproducido, en español, en nuestro libro La colonia cubana de París (1895-1898). La Habana, 1984, Anexo n. ${ }^{\circ}$ 32, págs. 367-369. 
Esta es la posición genuina de un republicano francés de origen antillano, solidario del Comité Francés de Cuba Libre. Sería exagerado tenerla por una línea de conducta antillanista, porque satisfecho del orden republicano que rige en las Antillas francesas, no aspira a su independencia política.

En las demás Antillas menores, donde tampoco en parte alguna se planteaba esta última cuestión, la guerra de independencia de Cuba no parece haber provocado en la población ni grandes temores ni locas esperanzas. Tal vez sea oportuno examinar aquí el caso jamaicano.

Jamaica pertenece más bien a las Antillas mayores; por esto y por su proximidad a Cuba acogió permanentemente desde 1868 a independentistas cubanos perseguidos (muchos de ellos negros y mulatos) que allí se instalaron (vegas y fábricas de tabaco) y desde allí "laboraron", aprovechando cierta corriente de simpatía local y cierta complicidad de la administración británica, tradicionalmente antiespañola, en Kingston. Cuando José Martí visitó a los cubanos de Jamaica, en octubre de 1892, un periodista de Kingston le entrevistó con marcada benevolencia y dio a conocer, por otra parte, el saludo final que dirigiera el líder revolucionario a la concurrencia cubano-jamaicana, agradeciendo en particular "la bondad y hospitalidad demostradas por el gobierno y el pueblo jamaicano a los exiliados cubanos". ${ }^{2}$ De hecho la causa cubana encontró en Jamaica, en 1895, una apreciable base de comprensión y acción.

\section{Desde las Antillas independientes}

En 1895, en las dos repúblicas independientes de las Antillas - Haití y la República Dominicana-, el poder está concentrado en manos de jefes militares. ${ }^{3}$ Entre ambas, con el tratado fronterizo de 1874, han cesado las guerras continuas de los años 40 y 50 y los hostigamientos ulteriores. Prevalece cierta coexistencia pacífica y se adoptan ciertas actitudes paralelas. En particular respecto al peligro de ingerencia, intervención y hasta

2 The Colonial Standard and Jamaica Dispatch, Kingston, 13 de octubre de 1892. Citado por Gonzalo de Quesada y Miranda: "Martí en Jamaica", Anuario Martiano, n. ${ }^{\circ}$ 5, La Habana, 1974, pág. 48.

3 El General Ulises Heureaux ("Lilís") detenta el poder a partir de 1892, "reelecto" por cuarta vez en ese año. Desde que asumió su primer mandato, se sucedieron en la presidencia de Haití los Generales Salomon, Légitime y, desde 1889, Hippolyte. 
anexión que bajo cualquier pretexto puede brotar desde Washington, desde donde se miran con un interés nada disimulado las magníficas posiciones del Môle Saint-Nicolas y de la Bahía de Samaná. Quienes en Haití y la República Dominicana intentaron cederlas, tuvieron que retroceder o fueron expulsados del poder. De modo que si los gobiernos - y en especial el de la dictadura dominicana - van creando, por el endeudamiento público, las condiciones de la sumisión de sus respectivos países a los intereses norteamericanos, reafirman pública y enfáticamente su plena soberanía, a veces de manera más espectacular que en las repúblicas del continente donde el peligro parece más lejano.

Francia absorbe el café haitiano y Alemania el tabaco dominicano; Francia ejerce una influencia cultural dominante en ambos países, donde el peso de los Estados Unidos es el que crece más sin embargo. Estas son las tres potencias cuyas decisiones y relaciones interfieren en la vida y la diplomacia de Haití y la República Dominicana, relegando a España a un segundo plano.

Resulta de ello una actuación ambigua ante la reanudación de la guerra de independencia cubana. El impacto de las guerras precedentes, la cercanía del campo de batalla, la presencia activa de exiliados cubanos en su territorio, el celo de los no menos activos agentes españoles, todo ello obliga a los dos gobiernos, molestos, a que se definan y a veces a que intervengan. Por un lado saben justificada la guerra emancipadora, fundadora de la propia legitimidad de los Estados que encabezan. Por otro lado, la temen porque puede concluir en una expansión de EEUU en la región. Indisponerse con España puede conciliar la simpatía norteamericana, pero puede también acarrear el descontento francés. Apoyar a España puede, a la larga, traer un mayor provecho que un apoyo franco a la causa cubana, pero la opinión pública no lo entendería. Esta ambigüedad es la que caracteriza la política de muchas repúblicas latinoamericanas que afrontan un dilema parecido y en las que se impone, por cálculo, un deber de supervivencia nacional en detrimento de los deberes de solidaridad continental. Política de expectativa más que de compromiso, de todas formas.

Basta leer algunas piezas de la correspondencia diplomática o algunos informes de los agentes secretos de España para quedar enterado del grado de colaboración entre las autoridades haitianas y las españolas en lo que concierne a la persecución de los cubanos independentistas. A petición del cónsul español, el presidente haitiano ordena que se arreste a José Martí y a Máximo Gómez en el momento en que intenten salir del país rumbo a las 
costas orientales de Cuba. ${ }^{4}$ La actitud del presidente dominicano revela mayor duplicidad, bastante comparable a la del presidente mexicano Porfirio Díaz en la misma coyuntura. ${ }^{5}$ Emilio Rodríguez Demorizi está convencido de que Lilís era adicto a Cuba, pero que no lo quería proclamar. Entregó dinero en Catimini a Martí y Gómez. ${ }^{6}$ En realidad, parece que "a todos interesaba el secreto", según contó uno de los intercesores cubanos.

¿Cuál era la motivación íntima del general Heureaux (Lilís)? Algunos historiadores estiman que él abrigó hasta el final sentimientos antiespañoles, heredados de la época de los gobiernos "azules". ' Otros que, en el fondo, aparentaba agradar a todos a la vez porque quería salir del aislamiento y apuro en que se ahogaba su gobierno. Al tener a todos los protagonistas en su mano y a raya, podía esperar sacar el mayor beneficio - tanto nacional como personal - a la hora de las ineludibles y difíciles negociaciones financieras. Sea lo que fuere, valiéndose de la olímpica posición de principio que era que la República Dominicana no dividía el mundo entre europeos y americanos, el dictador se atrevió a sugerir una mediación ¡norteamericana! para concluir con la guerra hispano-cubana, y a abogar por la constitución de una Comisión Internacional de Arbitraje mixta europeo-americana. ${ }^{8}$

Los cubanos y puertorriqueños estaban divididos también. Unos no deseaban pactar con el tirano que perjudicaba la república y ultrajaba la democracia. Otros, desconfiados, Ramón E. Betances entre ellos, dudaban de su sinceridad, conocedores de cómo había desterrado a los amigos reales de la independencia cubana (a Gregorio Luperón concretamente). Hasta hubo quien, como Eugenio María de Hostos, llegó a pensar que la independencia de Cuba y Puerto Rico se conseguiría mediante la eliminación de la dictadura dominicana.

4 Sarabia, Nydia: Notas confidenciales sobre Cuba (1870-1895). La Habana, 1985. pág. 218. La orden no se hizo efectiva por la retención que del telegrama hizo un empleado cubano de la compañía.

5 Unos hallazgos recientes en el Archivo Porfirio Díaz, de la Universidad Iberoamericana de México, establecen que José Martí fue a entrevistarse con el caudillo mexicano en el Palacio presidencial en agosto de 1894, y dan mayor crédito a los que defendieron que éste hizo una entrega personal de 20.000 \$ al delegado del PRC. Véase "Martí en México. Nuevos documentos", Anuario del Centro de Estudios Martianos, n. ${ }^{\circ}$ 14, La Habana, 1991, págs. 11-15.

6 Esa entrega de 2.000 pesos oro se efectuó por conducto del gobernador de Montecristi. Rodríguez Demorizi, Emilio: Martí en Santo Domingo. La Habana, 1953, pág. 332.

7 Gaillard, Roger: L'Etat vassal (1896-1902). Port-au-Prince, 1988, pág. 262.

8 Correspondencia Diplomática de la Delegación Cubana en Nueva York durante la guerra de la independencia de 1896 a 1898. La Habana, 1943-1946, t. IV, págs. 155-157, donde se reproduce la carta de Ulises Heureaux al presidente Cleveland, del 11 de abril de 1896, en la que formula esa idea de la mediación norteamericana. 
"Es indudable —escribió Hostos a Luperón— que el paso previo es la liberación de la República Dominicana, que, una vez libertada de su actual ignominia, y sujeta al régimen político, económico y administrativo que ya hubiera podido asegurar su desarrollo, prosperidad e influencia..., sería el centro natural y fecundo de reunión, concepción y ejecución de los planes que los Antillanos deseosos de asegurar el porvenir de las Antillas pudieran formar.

... En el fondo de las cosas, es tan esencial la libertad de Quisqueya para la independencia en Cuba y Puerto Rico que si acaso la de Cuba sobreviene sin ella, lo que es la de Puerto Rico y la Confederación, no". ${ }^{9}$

No todos los cubanos y puertorriqueños compartían esta estrategia de lucha, pero casi todos confiaban más en el apoyo de los sectores populares de la República Dominicana que en el de su gobierno sin prestigio ni brújula. Les asistió la razón. Desde que Martí, acompañado de Gómez, recorrió la República Dominicana en 1892 hasta la separación de Cuba de España a fines de 1898, la actividad a favor de la Cuba insurrecta alcanzó en ese país - pese a las trabas y las obligaciones de discreción - un importante nivel. Fuera de los EEUU, es el país en cuyo seno surgió y se desarrolló el mayor número de clubes revolucionarios. ${ }^{10}$ En vísperas de la disolución del Partido Revolucionario Cubano (PRC) y suspensión de Patria, el Cuerpo de Consejo que demostró mayor disgusto - estimando que realmente no estaba lograda la independencia absoluta de Cuba y Puerto Rico— fue el de Santo Domingo. ${ }^{11}$

En Haití, la labor de los clubes revolucionarios cubanos fue también de gran ayuda, aunque por la vigilancia gubernativa y sobre todo por razones de idioma y cultura fue inferior a la de los clubes radicados en la República Dominicana. ${ }^{12}$ Esos clubes, en uno y otro caso, reunían a cubanos (y puertorriqueños) con nacionales, haitianos o dominicanos. Pero es verdad, tanto por las razones arriba aducidas como por la política atractiva que siguieron los gobiernos "azules" a fines de la Guerra de los Diez Años, que

9 Carta de Eugenio María de Hostos al general Gregorio Luperón, 6 de noviembre de 1895. En Hostos: Obras. La Habana, 1976, págs. 137-138.

10 En su libro La emigración cubana y la independencia de la Patria (La Habana, 1953), Juan J. E. Casasús enumera los nombres de 21 clubes patrióticos en la República Dominicana (pág. 219). Menciona sólo ocho clubes similares en Haití.

11 El manifiesto del 16 de septiembre de 1898 de los 14 clubes que lo firmaron reza explícitamente: "El PRC no ha concluido su obra: él se fundó para obtener la independencia absoluta de Cuba". Patria, n. ${ }^{\circ}$ 501, New York, 19 de octubre de 1898.

12 Ejemplo de actividad: para colectar fondos "en Haití, se ha organizado una estudiantina, formada por 17 cubanos y 12 de otros países, en Port-au-Prince recorre las calles y recauda gruesas cantidades, al extremo de que en 24 de febrero [1896], Francisco Mir envía 361 pesos". Casasús, Juan J. E.: La emigración cubana..., pág. 305. 
en la República Dominicana los emigrados cubanos eran más numerosos -4 ó 5000 según las fuentes ${ }^{-13}$ que en la república vecina, donde no alcanzaban sino la décima parte y tenían más peso. Mediante inversiones en capital y tecnología en la industria azucarera, contribuyeron al despegue capitalista del país, mientras que en Haití quedó circunscrito su aporte económico a la artesanía y comercio del vestido y calzado. Muy presentes los dominicanos al lado de sus hermanos cubanos en el país —encabezando a veces los clubes revolucionarios ${ }^{-14}$ lo estuvieron también en la manigua, tras el más ilustre de ellos, el general dominicano-cubano Máximo Gómez.

\section{Desde las posiciones y aspiraciones antillanistas de los independentistas}

Al empezar la Revolución del 24 de febrero de 1895, ésta fue condenada en Cuba por casi todos los intereses económicos, todas las corporaciones, todos los partidos políticos, incluido el que pretendía representar el alma cubana: el Partido Liberal Autonomista (PLA). Ha sido frecuentemente comentado el inequívoco manifiesto de la Junta Central del Partido. ${ }^{15}$

Para dicha Junta Central, al romperse la paz se rompía el orden; la producción iba a disminuir, el deterioro de las relaciones sociales iba a aumentar y, con él, la inseguridad y la violencia; se abría un período peligroso e incierto si el movimiento armado no era sofocado inmediatamente. Por esta razón, la Junta Central acudió apresurada y vigorosamente en defensa del orden colonial, brindando sus servicios, como lo hiciera ya al inicio de la Guerra Chiquita en 1879, para desacreditar, aislar y aplastar a los rebeldes, tildados de gente irresponsable y de la peor ralea.

Detrás de la defensa de los intereses económicos que se expresan a través de la Junta Central del PLA — la gran propiedad rural y la exportación de azúcar en primer lugar-, esta actitud traduce una concepción de la

13 Nelson Carreño, en su Historia económica dominicana (Santo Domingo, 1989, pág. 23) dice "aproximadamente 4.000". Frank Moya Pons, en diversas oportunidades y en especial en su Manual de Historia Dominicana (9. a ed. Santo Domingo, 1992, pág. 407), habla de "unos 5.000 exiliados".

14 El ex-presidente de la República Francisco Gregorio Billini presidía el club "Máximo Gómez"; el intelectual Federico Henríquez y Carvajal presidía el club "27 de Febrero"; etc.

15 El manifiesto de la Junta Central del PLA — 4 de abril de 1895— censura a los "conspiradores, irresponsables de hecho, que han vivido muchos años lejos del país, cuyo verdadero estado desconocen ... Y [que] sólo ha[n] conseguido arrastrar, salvo pocas excepciones, a gentes salidas de las clases más ignorantes y desvalidas de la población". Según el texto ofrecido por El País, La Habana, 5 de abril de 1895 . 
nación varias veces expuesta por los líderes autonomistas. Según ellos, por justificado que sea el descontento y, circunstancialmente, explicable el alzamiento, la guerra no es sólo una catástrofe, es un error, no tiene fundamento, no ofrece perspectivas. Según ellos, Cuba pertenece a la nación española. Su anhelo, permanente desde Arango y Parreño, lógico y vital, es la autonomía, la autoadministración, el self government dentro del Estado español. Si la autonomía es la aspiración esencial del pueblo cubano, la independencia es lo accidental, lo transitorio, lo indeseable en esa vía.

En un discurso de 1886 pronunciado por un alto y representativo dirigente autonomista - Rafael Fernández de Castro—, en términos que suscribían todos los jefes de la misma corriente política, el orador afirmó lo siguiente:

\footnotetext{
"De tal modo ha sido permanente esta tendencia de nuestro espíritu popular, que bien puede apreciarse como una ley de nuestra historia la eterna aspiración de Cuba a su autonomía, o sea a la consagración de su personalidad social y política dentro de la nacionalidad a que correspondemos... El separatismo no ha existido en Cuba más que como momentánea protesta de desesperación; nunca como aspiración permanente del país...

En tal concepto, su aspiración natural y legítima no ha llegado jamás a romper los vínculos que le unen con el pueblo, que al darnos vida nos dio su cultura, la lengua que hablamos, la historia que tenemos, la religión que profesamos, las glorias con que nos enorgullecemos y las leyes y costumbres que practicamos. Nunca ha sido incompatible la libertad de una colonia con la grandeza y dignidad de su Metrópoli... La tendencia anexionista era una manifestación de impotencia ... y la aspiración separatista era un movimiento de impaciencia". ${ }^{16}$
}

Fácil sería ironizar sobre este rechazo rotundo, antes de la guerra de 1895, a las impensables "soluciones" anexionista y separatista a los males de Cuba y sobre el discurso, posterior a la guerra, de los mismos individuos, ayer autonomistas y siempre hacendados y agricultores. Una circular dirigida a los propietarios, colonos y agricultores de la isla, en enero de 1899 , al encarar el futuro, acepta con alivio y satisfacción las "soluciones" de la "impotencia" y de la "impaciencia", cualquiera que sea el estatuto definitivo de Cuba, "ya sea como estrella solitaria en medio del mar de las Antillas, en forma de Estado independiente, ya sea como astro unido a la constelación americana, en forma de Estado autónomo, dentro de la federación de la Gran República". ${ }^{17}$

16 Fernández de Castro, Rafael: Para la historia de Cuba. T. I. Trabajos políticos. La Habana, "La Propaganda Literaria", 1892, págs. 99-102. Las citas proceden del discurso pronunciado en Puerto Príncipe (Cuba) el 3 de diciembre de 1886.

17 Ibídem, pág. 487. 
Llama la atención cómo en los textos orientadores de los autonomistas cubanos (y puertorriqueños también), en vísperas o a raíz de la guerra de Cuba, la preocupación constante es la "justicia para los anhelos del país y respeto por sus derechos e intereses" —que son los de los productores exportadores-, excluyéndose de esta justicia la justicia social, y de estos derechos e intereses los de las capas populares, y limitando los anhelos del país al territorio cerrado de una isla perdida en el mar de las Antillas.

Pero no todo fue conservadurismo y estrechez en el pensamiento antillano con motivo de la guerra de independencia, aunque fueron estas reacciones las de las fuerzas económicas y las tendencias ideológicas dominantes en Cuba y Puerto Rico. Por un lado, hubo quien vio en la guerra de Cuba el punto de partida de la realización futura de profundos cambios sociales y morales, y, por otro lado, hubo quien vio en esa misma guerra fecunda el punto de partida de la realización de una futura Confederación de las Antillas libres, agrupadas en torno a Cuba libre.

Para medir la fuerza de esa tendencia que veía en la "guerra necesaria" de Cuba la condición y el principio de una república inédita, más justa y más armónica, podemos apoyarnos tanto en el texto de las prédicas revolucionarias como en el testimonio de quienes iban a alistarse en las filas mambisas sobre la base de las promesas oídas y las ilusiones arraigadas, y con la convicción de que iban a cambiar la sociedad y el mundo. No hace falta extrapolar ni interpretar para comprobar la realidad de tal tendencia.

Basta leer hoy los artículos que el Delegado del PRC, José Martí, escribió semanalmente en Patria (Nueva York), de 1892 a 1895. Reiteradamente explica en ellos, dirigiéndose especialmente a los tabaqueros emigrados, que la meta de la Revolución es la independencia absoluta; que el fin de ésta es la república democrática, a la que suele calificar de "justa", "moral", "trabajadora", "cordial", "equitativa", etc.; que la justicia social y la dignidad individual serán los pilares de la política republicana, sus valores supremos, y que la república no será ingrata para con los pobres que crean en ella y trabajen por ella.

Para que el lector/actor entienda la naturaleza del compromiso, Martí expone que esto no resultará de milagro alguno ni de la adopción de ningún modelo extranjero. Esta república "para todos", por venir, está por inventar con la participación "de todos". Cuba, según él, debido a su experiencia histórica, su situación geográfica, su producción económica, su gente abierta y capacitada, está en condiciones, en un momento oportuno, de crear una república de tipo nuevo, alejada tanto de la república oligárquica 
del Norte como de las repúblicas despóticas o nominales del Sur. Para Martí, Cuba puede ser el mayor laboratorio de la democracia en la América Latina; como "ifutura Universidad americana!” la designó un día. ${ }^{18}$

No cabe duda que esta perspectiva de reconstruir la sociedad cubana sobre una base nueva y popular, una vez descartadas la dominación española y la amenaza anexionista, haya motivado el apoyo extraordinario que la clase trabajadora de los talleres de tabacos y de los campos de Cuba y la gente de color le tributaron al PRC, portador de tamaña esperanza.

Muchos trabajadores de ideas avanzadas - republicanos, socialistas, anarquistas - se lanzaron también a la guerra, o la sostuvieron desde los centros laborales, porque esta república, abierta a todos y con prioridad a ellos, sería abierta también, en su evolución posterior, a las aspiraciones más radicales. Escuchemos a uno de ellos, al tabaquero Enrique Creci, líder anarquista del proletariado habanero, cuando, al irse a la manigua en mayo de 1895 , lanza a sus compañeros, en la prensa anarquista de la capital, una exhortación a seguir su ejemplo:

\begin{abstract}
"Así pues, compañeros, si es verdad que la guerra de Cuba reviste un carácter esencialmente democrático, hasta el punto que los individuos que componen el partido revolucionario han llegado a declarar que con la independencia podrá el hombre "gozar del derecho al trabajo en una tierra libre"; si es verdad que la emancipación política de este país ha de ser precursora de la emancipación económica, y por consecuencia, —realizada la aspiración del obrero cubano de gozar de la libertad de su patria - ha de sernos dable propagar nuestros principios igualitarios sin que se estrellen nuestras predicciones en la desconfianza de los trabajadores, no cabe vacilar por más tiempo, y debemos resueltamente colocarnos al lado de los revolucionarios cubanos y luchar con denuedo por su causa, que es nuestra causa, ayundándoles a sacudir la dominación que sobre Cuba pesa y que es causa de tantas desdichas". ${ }^{19}$
\end{abstract}

Muchos de los voluntarios europeos alistados en el ejército mambí, los italianos y los franceses en particular, cruzaron el Atlántico con ese fin social y esa fe. ${ }^{20} \mathrm{La}$ ilusión fue grande entre quienes tenían conciencia de

18 "Albertini y Cervantes", Patria, Nueva York, 21 de mayo de 1892. En Martí, José: Obras Completas. La Habana, 1963-1973, t. IV, pág. 413.

19 Creci, Enrique: "A los trabajadores de La Habana", La Habana, 17 de mayo de 1895. Reproducido en El Archivo Social, La Habana, y luego en El Despertar, Nueva York. Tomado de Serrano, Carlos: Anarchisme et indépendance nationale à Cuba à la fin du XIXsiècle. Saint-Denis, 1986, pág. 76.

20 Desarrollamos el tema en el encuentro auspiciado por la AIETI en Madrid en mayo de 1996 sobre "El impacto del 98 en Europa y América Latina. Etica y Política a finales del siglo XIX". Las intervenciones grabadas deben publicarse en 1997. 
emprender una auténtica revolución desde abajo. Proporcionalmente grande fue luego la desilusión de los sobrevivientes al comprobar a fines de 1898 que las circunstancias no eran las esperadas. ${ }^{21}$

El otro aspecto utópico que revistió, al inicio, la guerra de 1895 fue que con la independencia de Cuba se iba a producir en las Antillas mayores de habla hispana un amplio movimiento solidario y convergente que conduciría a la unión, y hasta a la confederación, de las islas antillanas, en un momento de reequilibrio y recomposición mundial.

La idea, es sabido, había nacido antes de la guerra de 1868, promovida por los independentistas puertorriqueños Ramón Emeterio Betances y Eugenio María de Hostos. ${ }^{22}$ En 1895 renace, siempre viva bajo la pluma de Betances y Hostos, incansables abogados de la causa cubana en su lejano exilio, pero ahora retomada por gente de la nueva generación borícua (Sotero Figueroa) y por cubanos. Existen diferencias entre ellos en la formulación que hacen entonces de las formas posibles de la futura unión antillana; pero no las hay ni en la práctica solidaria ni en los propósitos perseguidos.

En lo que suele llamarse el testamento antillanista de José Martí - su última carta al amigo dominicano Federico Henríquez y Carvajal, del 25 de marzo de 1895- el prócer cubano afirmó: "Las Antillas libres salvarán la independencia de nuestra América, y el honor ya dudoso y lastimado de la América inglesa, y acaso acelerarán y fijarán el equilibrio del mundo". ${ }^{23}$ No hacía más que confirmar en carta privada lo que había desarrollado en la tribuna o en el periódico y que viene magníficamente estampado en dos artículos anteriores de Patria : "Las Antillas y Baldorioty Castro", de 1892, y "El alma de la revolución, y el deber de Cuba en América", de 1894.

En el primer artículo referido, cual obsesión, repite que las "tres Antillas hermanas", las "tres islas abrazadas de Cuba, Puerto Rico y Santo Domingo", "las tres vigías de la América hospitalaria y durable", "las tres

21 Véase por ejemplo la carta de Gualterio García a Tomás Estrada Palma, 14 de enero de 1899. Archivo Nacional de Cuba, Correspondencia de la Delegación del PRC en Nueva York, carta n. ${ }^{\circ} 1396$.

22 Desarrollamos el tema del antillanismo de Hostos y Betances en trabajos anteriores, y últimamente en España en una ponencia intitulada "La nación antillana: sueño y afán de El Antillano (Betances)" y recogida en La Nación Soñada: Cuba, Puerto Rico y Filipinas ante el 98. Aranjuez, 1996, págs. 25-36.

23 José Martí a Federico Henríquez y Carvajal, Montecristi, 25 de marzo de 1895. En Martí: Obras completas, t. IV, pág. 111. 
hermanas que de siglos atrás se vienen cambiando los hijos y enviándose los libertadores", "han de salvarse juntas o juntas han de perecer". ${ }^{24}$

En el segundo, más explícito, expone que

\begin{abstract}
"en el fiel de América están las Antillas, que serían, si esclavas, mero pontón de la guerra de una república imperial contra el mundo celoso y superior que se prepara ya a negarle el poder - mero fortín de la Roma imperial—, y si libres - y dignas de serlo por el orden de la libertad equitativa y trabajadora- serían en el continente la garantía del equilibrio, la de la independencia para la América española aún amenazada y la del honor para la gran república del Norte, que en el desarrollo de su territorio — por desdicha, feudal ya, y repartido en secciones hostiles — hallará más segura grandeza que en la innoble conquista de sus vecinos menores, y en la pelea inhumana que con la posesión de ellas abriría contra las potencias del orbe por el predominio del mundo. No a mano ligera, sino como con conciencia de siglos, se ha de componer la vida nueva de las Antillas redimidas. Con augusto temor se ha de entrar en esa grande responsabilidad humana... Es un mundo lo que estamos equilibrando: no son sólo dos islas las que vamos a libertar... Un error en Cuba, es un error en América, es un error en la humanidad moderna”. ${ }^{25}$
\end{abstract}

Estas líneas de Martí, como las cartas y artículos de Betances y Hostos, o como el combate de Luperón, Henríquez y Carvajal y Gómez, revelan y delinean el profundo plan antillanista que todos acariciaban, como medio para conseguir la independencia de Cuba y Puerto Rico, inseparables, y luego para garantizarla, y como fin para instaurar una república sólida y novedosa, que aglutine paulatinamente a las Antillas menores, que impida el avance del expansionismo norteamericano, que sustraiga a las rivalidades imperiales esa porción antillana del mundo, que mantenga así la paz mundial amenazada por las ambiciones de dominación del acceso al canal interoceánico y que, respecto a la América Latina reincorporada, sirva de factor de progreso y de referencia democrática.

Concebida así, la guerra de independencia de Cuba, al volver a encenderse en 1895, no era sólo la conclusión de un movimiento interrumpido en 1878 y 1880, no era sólo el pretexto a una batalla entre dos imperios que iban a medirse. Desde Cuba, desde las Antillas, desde el exilio antillano, en el pensar y el sentir "antillanistas" de notables cubanos, puertorriqueños, dominicanos y demás antillanos (haitianos como Firmin, por ejemplo), en

24 "Las Antillas y Baldorioty Castro", Patria, Nueva York, 14 de mayo de 1892. Ibídem, t. IV, págs. 405-410.

25 "El tercer año del Partido Revolucionario Cubano. El alma de América, y el deber de Cuba en América", Patria, Nueva York, 17 de abril de 1894. Ibídem, t. III, págs. 142-143. 
la mente exaltada de algunos obreros que creían en la revolución social, la guerra de 1895 era el comienzo de un movimiento formidable que debía cambiar la faz del mundo en la región, "desatar a América y desuncir el hombre", según la expresión de Martí (1893). El análisis de aquella dimensión utópica de la guerra de Cuba no debe estar ausente un siglo después, no sólo porque varios jefes y ciertos combatientes abrigaban tal esperanza, sino también porque hoy nadie puede certificar que aquella utopía murió allí para siempre. 